\title{
Dynamics of Gender-Specific Behaviors in the Digital Educational Environment
}

\author{
https://doi.org/10.3991/ijim.v15i24.27879 \\ Jel̦ena Badjanova ${ }^{(凶)}$, Dzintra Iliško, Svetlana Ignatjeva, Margarita Nesterova \\ Daugavpils University, Daugavpils, Latvia \\ jelena.badjanova@du.Iv
}

\begin{abstract}
During the social distancing, an increasing number of people use communication applications, various types of digital tools and programs. Various video conferencing platforms are regularly used in the educational environment. The study presents the analyses how intensive is the use of Information and Communication Technologies (ICT) in the educational environment and how it can change cognitive-behavioral gender differences. This is particularly important to pay a special attention to the analysis of gender as a dynamic category, to take into account the processes of gender socialization and transformation of gender identification in the changing social environment. The research methods also included a set of additional methods, such as a focus group on different aspects of gender-specific behavior in the digital learning environment, putting together collages, as well as the method of the unfinished sentence related to the impact of ICT on teachers' professional development and well-being. In the course of the study, it was recognised that the design of social models of male and female gender-specific behaviour includes more than the basic gender identity and gender stability: in today's society, there is a multiplicity of views on the similarities and differences of gender-specific behaviours, and a rapid change in the accepted social guidelines and behavioural patterns is in progress, socio-cultural norms that define the psychological characteristics of women and men, their patterns of behaviour.
\end{abstract}

Keywords - the similarities, differences, mid-maturity, gender-specific behaviours

\section{Introduction}

\subsection{Introduction and social aspects of the topicality of the research}

The ambiguous evidence on differences between the biological sex and gender role require further research. Therefore, the theoretical foundation of the study is based on both, the classical theories and the results of recent studies on some aspects of gender differences and similarities. The focus of modern science is on an individual's cognitive-behavioural interactions, as well as on the cognitive-behavioural-gender interactions. In order to analyse the concept of gender in detail, different theories and approaches are described in general, as well as the views of various psychologists and authors of scientific studies in the field of social psychology. 
In their previous studies, the authors of the present paper have already explored the similarities and differences of gender-specific behaviours of the residents of Latvia in the age groups of youth, early and mid-maturity. Likewise, the socio-cultural factors that might contribute to the Latvian and Bulgarian residents' motivation for success across various age and gender groups have also been studied.

L. Kohlberg [1] in his theory of cognitive development (cognitive-developmental theory) argued that all information relating to gender-specific behaviour is reflected in our consciousness in the form of gender schemes.

A paradigm was adopted on:

1) Gender permanence. At this stage, children become aware that surface changes or actions do not affect gender. Even when a girl wears jeans or plays football, or when a boy has long hair or a keen interest in embroidery, the child's gender remains intact.

2) Gender stability. At this stage, a child admits that men remain men, but women remain women. Little boys stop thinking they will grow up to be a mum, but little girls lose their hopes of ever becoming Batman.

However, the question remains as to how an individual changes his or her gender role in ontogenesis/over the course of one's life, regardless of the childhood experiences and awareness.

It may be established that the essence of the gender construction is polarity and contrasting. The gender system reflects the asymmetric cultural assessments and expectations that are attributed to people depending on their sex. From a certain point of time, in every society where socially attributed characteristics diverge into two gender types (tags), the social roles culturally regarded as secondary are attributed to one biological sex. It does not matter what kind of social roles they are: they can vary in different societies, yet those that are attributed to and determined for women are judged to be inferior (secondary). Social norms change with time, but the gender asymmetry remains. However, E. Maccoby and C. Jacklin [2], as well as S. Bem [3] stated that the main feature of a gender is the behavioural aspects pertaining to a certain social gender, regardless of the biological sex: gender-specific behaviour patterns are acquired during a person's lifetime and they are typical of a particular culture or society. The authors claim that a set of norms containing general information on the characteristics of each sex is what can be termed as gender roles. S. Bem believes that population growth, mechanization of manufacturing and economic crises have lead to a situation when it becomes more and more dangerous for men to determine their value according to their financial opportunities. By insisting on seeing this quality as typically male, we doom most men to failure. According to the author, traditional roles in nowadays society obviously do not function properly. Thus, it can be argued that, in the social model of male and female gender-specific behaviours, S. Bem attempts to find a way to help a person get rid of the restrictions which are imposed on the behaviour and psychology of men and women by the traditional stereotypic thinking and which, in essence, are merely a conditional attribution to one or the other sex [3]. Many aspects of S. Bem's theory comprise the regularities of the manifestations of femininity, masculinity and androginity.

In Europe and all over the world, researchers have studied the impact of sex, age and gender differences on self-efficiency and decision making [4]. There was an 
increased interest in exploring the potential for the use of IT technologies to determine the cognitive-behavioural gender differences $[5,6]$. Likewise, the cognitive aspects in the field of education were frequently studied. For instance, many researchers [7] have found that the lack of significant gender differences means that the effect of the phenomenon under study is the same for both, men and women. If the study frequency is the same, regardless of the student's age and gender, it means that the students demonstrate the same patterns of behaviour regarding the study frequency. There is no gender difference in preference of a certain type of study, yet there is an age difference. Likewise, gender and age are not related to the study environment. In numerous researches, the proposed methodologies for researching self-learning with adolescents may be observed more frequently: whether the age and sex have an impact $[8,9]$.

Remarkable research was conducted in the field of communication [10]. Explaining the differences between men and women in using unethical tactics for negotiation. The stability of this ethical difference served as a reason for many studies that focused on why men more frequently than women tend to use unethical methods in negotiation. Widespread responses to both answers share a common theme: a compromise between caring for oneself and others. Overall, the results confirmed that competition and empathy are constituents of the gender constructs. Despite the credible assumption that there are gender differences in social affiliation, different studies yield ambiguous results.

For instance, arguing that the female, emotionally oriented decision is associated with a higher level of depression than the male, problem-oriented decision. The women who are more feminine and accept traditional female gender roles have a lower self-esteem, consider stressful occurrences more unpleasant as well as are more prone to yield to group pressure. Androgynous women displaying some male traits are less subject to stress and experience a higher level of psychological wellbeing. Likewise, androgynous persons are more sensitive to minute differences between specific stressful occurrences, which reflects in a more flexible use of various strategies and their ability to distinguish effective survival strategies. In addition, their flexible pattern of strategies is more prudent than casual. Besides, androgynous behaviour also accounts for a lower level of social alarm [11].

The modern world is changing faster than ever. The processes of integration and globalisation enable people to travel easily around the world, work or study outside their home country $[12,13]$. Oftentimes, people embark on a new life, not only geographically, but also culturally distanced from previous traditions. The global migration presupposes either living in a different cultural context or in a multicultural society, behaving in accordance with cultural models or rules that are binding to this society. There are different behavioural models in each culture [13, 14]. Thus, the above-mentioned gender psychology theories and concepts allow for differentiation of the following categories:

1) gender differences;

2) gender socialization;

3) female psychology;

4) male psychology;

5) gender relationship psychology;

6) leadership gender psychology. 
The view on sex and gender as discursive constructions led to the erosion of boundaries between these concepts. In addition, subjective identity is always situational and in a multi-faceted relationship with others, instead of mere gender characteristics.

While the definition of a particular role may depend on a culture, we can surmise that since gender roles are preserved through socialization processes, they rarely undergo any material changes. Therefore, the authors of the present article, due to a close cooperation with one of the Bulgarian universities, decided to carry out identical studies.

The following chapter describes the course of the study, for which the following objective was set: by adapting S. Bem's survey, to explore and differentiate the male and female gender-specific behaviours in the early and mid-maturity age groups.

Consequently, the main aim of this research is to explore gender-specific behaviours of Bulgarian students and teachers in the digital educational environment.

\section{Methodology}

The gender and gender identity studies is a particularly topical issue in experimental psychology. The reason for that is lack of a uniform diagnostic tool. The situation is even more complicated by the fact that although the topic is well researched, these studies mainly focus merely on exploring the differences in thinking, memory, behaviour and communication. The study was conducted in the time frame of 2020-2021. The research design describes the entire research process, from defining the problem to outlining the results of the study. The type of the present study is qualitatively quantitative, non-experimental and it takes place in real-life environmental conditions in different regions of Bulgaria, as well as online, with a prior presentation of the instruction on filling out the questionnaire to each respondent.

Qualitatively quantitative methodology was used to conduct the present research. In the course of the empirical study conducted during the 2020-2021 period, quantitative methodology was applied using an adapted S. Bem's Sex-Role Inventory (BSRI) survey. The study involved 150 respondents in the early and mid-maturity age groups (20-60-year olds). The authors of the present paper also used different methods to research gender-specific behavioural differences in their studies. However, S. Bem's BSRI methodology has been most effective so far.

Participant selection strategy: non-probable sampling was used to select the respondents for the survey

The research subject: the survey was used to diagnose the psychological gender and determine the degree of androginity, masculinity and femininity in a personality, thus permitting to distinguish the type of personality: masculine, feminine or androgynous.

Research contingent: adults.

Research methodology: the questionnaire contains 60 statements. The methodology includes instructions for the survey, an answer form and recommendations for the processing and interpretation of the obtained results. Theoretical basis: the theoretical basis of this methodology is S. Bem's concept of androginity [14-17]. 
The authors have used the focus group methods and the method of the unfinished sentence which was used by the authors as an additional tool. Participant selection strategy: random sampling was used to select the respondents.

The following questions were raised: (1) What are male and female gender-specific behaviours in the early and mid-maturity age groups of students and teachers who intensively use Information and Communication Technologies (ICT) in the educational environment? (2) Are there any similarities and differences between the male and female gender-specific behaviours in the early and mid-maturity ages?

\section{Results and discussion}

Data were processed using the SPSS (Statistical Package for the Social Science) 20.0 software version. Methods of statistical data analysis: for testing the reliability and coherence of the indicators, for determining the distribution of results, for analysis of the variance of results, the parametric one-factor analysis of variance (ANOVA), descriptive statistics.

For the purpose of the study, age groups of men and women were distinguished according to E. Erikson's [14, 18-20] stages of psychosocial development. The first group of respondents was comprised of men and women aged 20-25 (early maturity); the second group of respondents included men and women aged 26-60 (Table 1).

Table 1. Gender and age group cross tabulation

\begin{tabular}{|c|c|c|c|c|}
\hline \multirow[b]{2}{*}{ Gender } & \multirow[b]{2}{*}{$(\%)$} & \multicolumn{2}{|c|}{ Age Group } & \multirow[b]{2}{*}{ Total } \\
\hline & & $\begin{array}{c}\text { From } 20 \text { to } 25 \\
\text { Years Old }\end{array}$ & $\begin{array}{c}\text { From } 26 \text { to } 60 \\
\text { Years Old }\end{array}$ & \\
\hline \multirow{3}{*}{ Female } & Count & 52 & 30 & 82 \\
\hline & $\%$ within gender & $63.4 \%$ & $36.6 \%$ & $100.0 \%$ \\
\hline & $\begin{array}{l}\% \text { within age } \\
\text { group }\end{array}$ & $58.4 \%$ & $49.2 \%$ & $54.7 \%$ \\
\hline \multirow{3}{*}{ Male } & Count & 37 & 31 & 68 \\
\hline & $\%$ within gender & $54.4 \%$ & $45.6 \%$ & $100.0 \%$ \\
\hline & $\begin{array}{l}\% \text { within age } \\
\text { group }\end{array}$ & $41.6 \%$ & $50.8 \%$ & $45.3 \%$ \\
\hline \multirow{3}{*}{ Total } & Count & 89 & 61 & 150 \\
\hline & $\%$ within gender & $59.3 \%$ & $40.7 \%$ & $100.0 \%$ \\
\hline & $\begin{array}{l}\% \text { within age } \\
\text { group }\end{array}$ & $100.0 \%$ & $100.0 \%$ & $100.0 \%$ \\
\hline
\end{tabular}

Assessment of the survey results showed that women in general have a more pronounced Femininity index $(M=2.53)$ than Masculinity index $(M=2.48)$, however the Androginity index is also pronounced $(\mathrm{M}=0.12)$. Yet, when comparing the results in 
the two age groups, we can recognize that the Masculinity index is more prominent in women aged 20-25 $(\mathrm{M}=2.53)$ than in women aged 26-60 $(\mathrm{M}=2.39)$. Likewise, it was established that the Femininity index is higher in women aged 20-25 $(\mathrm{M}=2.59)$ than in women aged 26-60 $(\mathrm{M}=2.43)$.

On the other hand, in men in general the Masculinity index $(\mathrm{M}=2.48)$ is higher than the Femininity index $(M=2.20)$. The Androginity index not pronounced $(M=-0.65)$. However, when comparing the results in the two age groups, it was discovered that the Masculinity index is higher in men aged 26-60 $(\mathrm{M}=2.51)$ than in men aged 20-25 $(\mathrm{M}=2.45)$. Yet, the Femininity index $(\mathrm{M}=2.20)$ remains at the same level.

When comparing the two age groups of women and men, it was established that particularly in the first age group, women $(\mathrm{M}=2.53)$ have a higher Masculinity index than men, whereas in the second group vice versa - men $(\mathrm{M}=2.51)$ have a higher Masculinity index than women $(\mathrm{M}=2.39)$. On the other hand, the Femininity index in women aged 20-25 $(\mathrm{M}=2.59)$ is higher than in men $(\mathrm{M}=2.20)$, and the same is true for women aged 26-60 (M = 2.43) who also have a higher Femininity index than men in the same age group $(\mathrm{M}=2.20)$ (Figure 1).

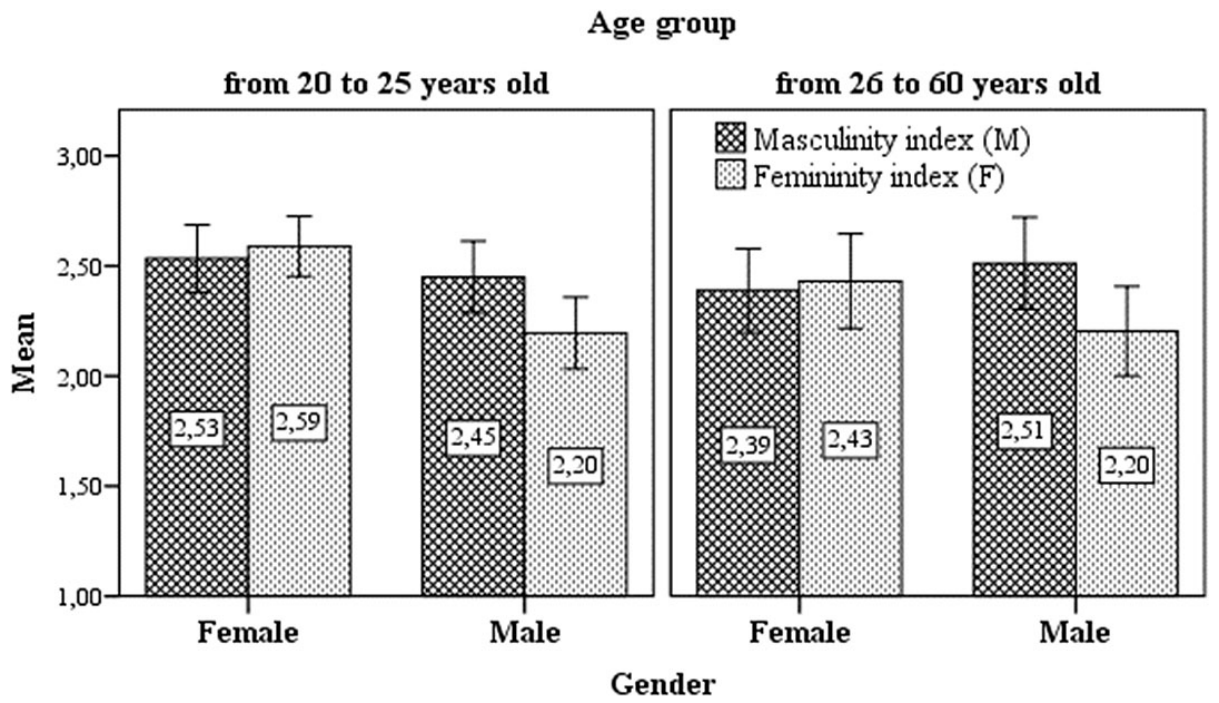

Error bars: $95 \% \mathrm{CI}$

Fig. 1. Masculinity and Femininity index in the two age groups

According to the dependent samples t-test results, for women there are no significant differences between the Masculinity and Femininity indexes. For men in both age groups the Masculinity index is higher than the Femininity index, and these differences are statistically significant (the level of statistical significance of the criterion is less than 0.05 ) (Table 2). 
Table 2. Paired samples test results

\begin{tabular}{|c|l|l|c|c|c|}
\hline Gender & \multicolumn{1}{|c|}{ Age Group } & \multicolumn{1}{c|}{ Index } & t & Df & Sig. \\
\hline \multirow{5}{*}{ Female } & $\begin{array}{l}\text { from 20 to 25 } \\
\text { years old }\end{array}$ & $\begin{array}{l}\text { Masculinity index } \\
(\mathrm{M}) \text {-Femininity } \\
\text { index (F) }\end{array}$ & -1.082 & 51 & 0.284 \\
\cline { 2 - 6 } & $\begin{array}{l}\text { from 26 to 60 } \\
\text { years old }\end{array}$ & $\begin{array}{l}\text { Masculinity index } \\
(\mathrm{M}) \text {-Femininity } \\
\text { index (F) }\end{array}$ & -0.639 & & 0.528 \\
\hline \multirow{5}{*}{ Male } & $\begin{array}{l}\text { from 20 to 25 } \\
\text { years old }\end{array}$ & $\begin{array}{l}\text { Masculinity index } \\
(\mathrm{M}) \text {-Femininity } \\
\text { index (F) }\end{array}$ & 3.136 & 36 & 0.003 \\
\cline { 2 - 6 } & $\begin{array}{l}\text { from 26 to 60 } \\
\text { years old }\end{array}$ & $\begin{array}{l}\text { Masculinity index } \\
(\mathrm{M}) \text {-Femininity } \\
\text { index (F) }\end{array}$ & 3.450 & 30 & 0.002 \\
\hline
\end{tabular}

In the age group of 20-25-year olds, the Masculinity index is higher for women than for men, but according to the independent samples t-test, these differences are not statistically significant $(\mathrm{t}=0.738 ; \mathrm{p}=0.463)$. In the age group of $26-60$-year olds, the Masculinity index is higher for men than for women, yet these differences also are not statistically significant $(t=0.648 ; \mathrm{p}=0.379)$. No significant differences in the Masculinity index across both age groups were observed with either women $(t=1.180$; $\mathrm{p}=0.242)$ or men $(\mathrm{t}=-0.477 ; \mathrm{p}=0.635)$. Figure 2 shows masculinity index in the two age groups.

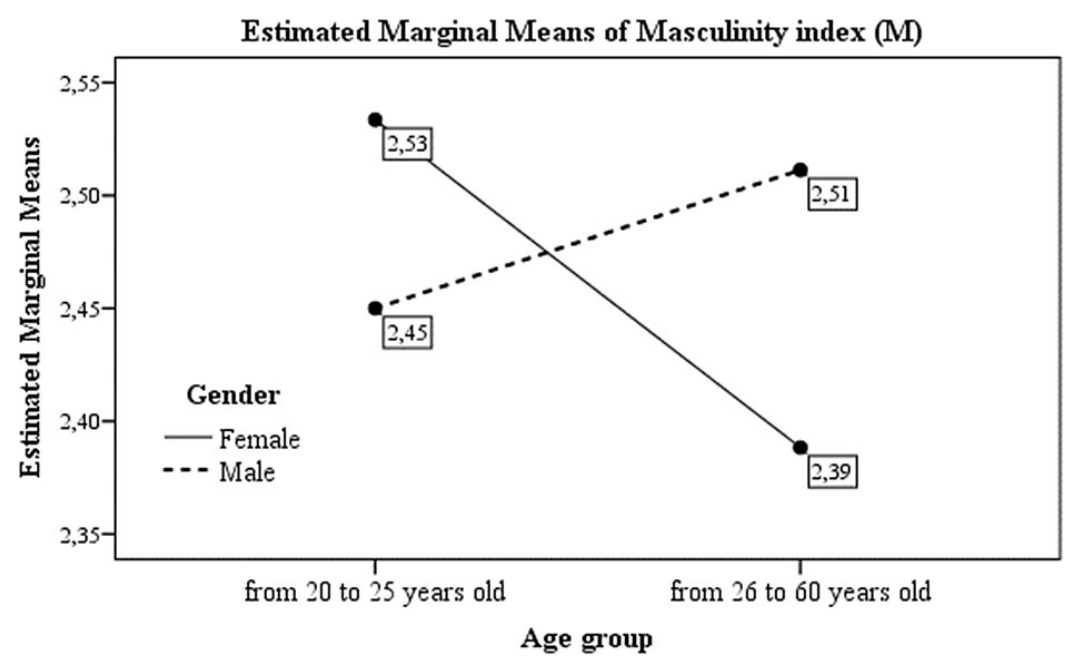

Fig. 2. Masculinity index in the two age groups

According to the independent samples t-test, in the age group of 20-25-year olds, we can observe statistically significant differences in the Femininity index for both, women and men $(\mathrm{t}=3.733 ; \mathrm{p}<0.001)$, and this index is markedly higher for women. 
In the age group of 26-60-year olds, there are no significant differences in the Femininity index for either men or women $(t=1.569$; $\mathrm{p}=0.122)$. For women aged 26-60, the Femininity index is lower than for women aged 20-25, but these differences are not statistically significant $(\mathrm{t}=1.316 ; \mathrm{p}=0.192)$ (Figure 3$)$.

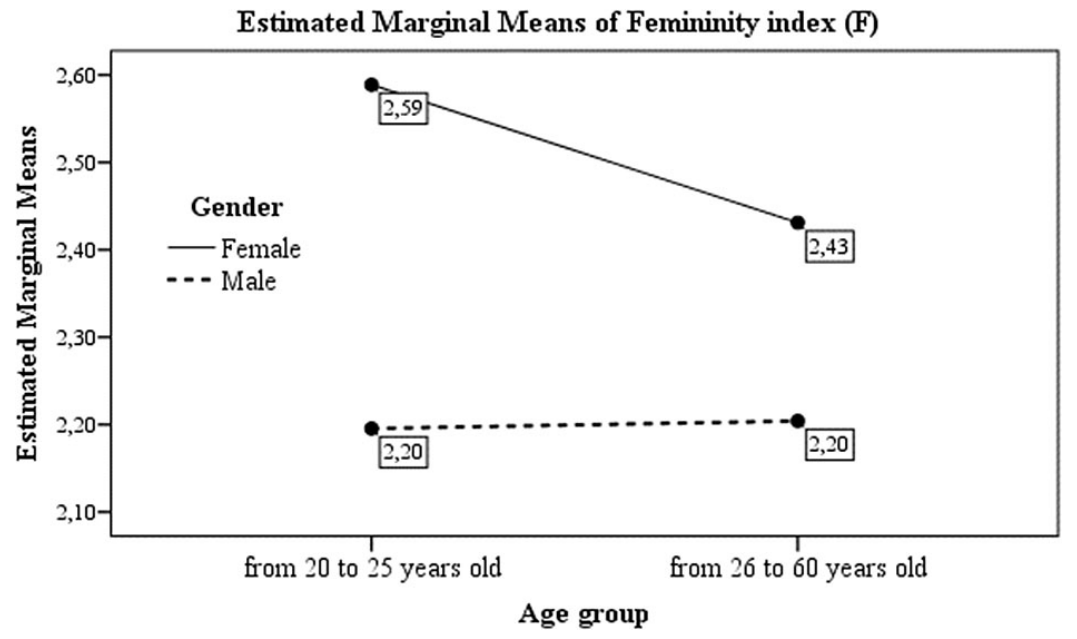

Fig. 3. Femininity index in the two age groups

As a result of the empirical research, the essence of male and female gender-specific behaviour was determined. On the grounds of the obtained survey results, the content and dynamics of gender-specific behaviours of Bulgarian males and females were interpreted in the early and mid-maturity age groups. Masculinity and Femininity scales were measured. A rather high Androginity index for both, men and women were determined in early and mid-maturity age groups.

In the second phase of the study, a focus group was organized with 10 female $(\mathrm{N}=5)$ and male $(\mathrm{N}=5)$ teachers. In the discussion with the interviewer, women demonstrated masculinity features in self-presentation and in defending their opinion about the usefulness of ICT in general and in professional activities. Women assessed positively digital competences and media literacy in order to develop their professional competences, as well as they worried less about the possibility of losing their job in a changing environment in line with the labor market demands.

However, in the presence of men, they prefer displaying features of femininity because of fear of losing their femininity. This show that women adapt more easily, which is more indicative of androgyny.

Men are more aware of the need for a digital environment, not only in the field of education, but in the context of macroeconomics. Recognition of the positive results of men about the use of ICT in education and communication, as well as in the development of any professional skills will be useful for undertaking financial decisions and material economic and social responsibilities in general. The differentiation of women's and men's views corresponds both to the traditional division of social roles.

According to the opinion of respondents,' gender or social behavior is interpreted as a technology of self-representation with the help of various social institutions: family, 
education system, mass media, politics, law, language, art, science, fashion. However, gender is differentiated as a manifestation of various situations that are not particularly related to the fulfilment of a student's or educator's social roles. Respondents acknowledge that working in the digital environment is hampered by gender, especially women's emotionality and fragility in overcoming difficulties, in the process of acquiring new information related to the diverse use of ICT in the digital educational environment. Therefore, the possibility of women to react faster, to make decisions, to think more schematically and logically was discussed. In other words, this is safer to switch from femininity to masculinity in order to integrate more quickly and successfully into the business. Male educators are not disturbed by the digital educational environment, they are happy to adapt to the intensive use of ICTs.

The results of the focus groups showed that gender roles are good tools for psychological adjustment.

The analyses of multidimensional models of gender identity gained according to the results of incomplete sentence methodology indicates that a wide range of behavioral patterns were also discovered. In the environment of the students $(\mathrm{N}=57)$, as well as in the environment of teachers $(\mathrm{N}=37)$, the authors designed some recommendations:

1) It is important for the educators and institutions to take action to prevent bias in educational settings by overburdening students in the digital learning environment. The approach must be multifaceted. Educators should be aware of gender-specific behaviors and teach strategies to change these behaviors;

2) Female respondents recognize that teacher training should include strategies that balance the focus on male and female students and promote gender equality. The most important thing is that students themselves should be encouraged to overcome gender stereotypes in society, when in certain circumstances it is necessary to "turn on the signs of masculinity, androgyny in order to adapt and simply endure the load by attracting willpower";

3) From a men's perspective, the goal of education should be aligned with students' desired worldviews to motivate them to learn and succeed, thus increasing the adaptability and flexibility needed to live happily and meaningfully in a diverse society and global world.

\section{Conclusions}

Considering the obtained results of our study, it may be concluded that:

- both, male and female gender-specific behaviours in the early and mid-maturity age groups are marked by a tendency towards assuming a leadership position, regardless of gender or age, which characterises our group of respondents as generally more masculine and androgynous;

- Bulgarian men seek to maintain gender-relevant behavioural models, as indicated by the Masculinity and Femininity indexes;

- Bulgarian women differ from men in their androgynous behaviour, as evidenced by the high Masculinity index; 
- there are both similarities and differences between male and female gender-specific behaviours in the early and mid-mature age groups: the younger the women, the more prone they are to display signs of androgyny, and the older the men, the more masculine they become.

In the course of research, it was established that across all age groups both men and women display a rather high index of androginity. The authors believe that the evolution of the discussion on the issue of sex and gender lead to a denaturalization of the division of labour and psychological distinctions between women and men, drawing the focus on cultural "variations." That is, being a man or a woman in the society meant not only having certain anatomical features but also performing specific gender roles. Gender is shaped and constructed by the society as either a male or a female social model, which determines a person's position and role in the society and its institutes: family, political structure, economy, culture, education, etc. Some of the social norms penetrate our consciousness through television and popular literature, others we acquire directly, for instance, by experiencing public censure when we deviate from our expected gender-specific role and behaviour. The informational pressure is caused by the fact that by extending our knowledge of ourselves and the world, by trying to understand the position to be taken on specific social issues, we rely to a large extent not on personal experience but on the information provided by the surrounding environment.

In other words, sometimes we submit not merely because we are afraid of public condemnation, but because without the guiding effects from others we really do not know what to think, feel and do. In addition, we are turning to others for advice and following their example. We live in a civilisation shaped by humans, and without them it cannot be fully comprehended. Therefore, it can be argued that relying on others to expand our knowledge on social issues and on the world we inhabit in general contributes to adaptation. A person perceives his or her behaviour as correct as long as he or she observes the same behaviour among the members of the reference group.

Thus, it can be acknowledged that in the 21st century the phenomenon under study is that it is not the biological sex, but socio-cultural norms that define the psychological characteristics of women and men, their patterns of behaviour, types of pursued activity and professions. That it is necessary to extend the scope of possible gender configurations, taking into account the diversity of nature's cultural configurations.

There are no differences in the views of students and teachers on the effectiveness of the use of ICT in the educational environment, regardless of the gender of the respondents. However, the age of the respondents is what makes a difference: the older the respondents, the more likely they are eager to learn more about new things in order to cover the shortcomings of previous years or in order not to lose the job. It can be concluded that students and teachers are satisfied with the use of ICT in the educational environment.

In the context of the professional potential and economic future, all respondents considered it necessary to use ICT. The students also proposed recommendations to the teachers for working in the digital educational environment.

Thus, the participants are open to reform and change.

The results of the conducted empirical research show that a high index of Androginity dominates among the Bulgarian students and teachers in the digital educational environment, irrespective of the gender. This phenomenon remains little studied: the 
psychological theory and practice lacks data on the peculiarities of gender identity in relation to the use of Information and Communication Technologies. The findings of this study will help deepen the understanding of the development of person's gender identity in the period of change that education undergoes. Yet this aspect still deserves a much deeper research. The dominant research result showed the dynamics of the androginity phenomenon, regardless of age and gender, which has been increasingly debated in today's society. The basic assumption of recent studies is the following: the perspective of gender (behavioural) roles is that a person can behave in a traditionally masculine or traditionally feminine manner depending on the current situation, limitations and needs and yet remain in accordance with one's biological sex-either male or female. Consequently, the androginity phenomenon is a good indicator of an individual's psychological adaptation.

Thus, the participants are open to reform and change.

\section{$5 \quad$ References}

[1] Kohlberg, L. A. (1966). A cognitive-developmental analysis of children's sex role concepts and attitudes. The development of sex differences, 82-173.

[2] Maccoby, E. E. (1974). Jack! in, CN The psychology of sex differences. Stanford, C alif.: Stanford University Press.

[3] Bem, S. L. (1974). The measurement of psychological androgyny. International Journal of Consulting and Clinical Psychology, 42:155-162. https://doi.org/10.1037/h0036215

[4] Jaradat, M. I. R. M., Imlawi, J., \& Al-Mashaqba, A. M. (2018). Investigating the moderating effects of self-efficacy, age and gender in the context of nursing mobile decision support systems adoption: a developing country perspective. Int. J. Interact. Mob. Technol., 12: 113-129. https://doi.org/10.3991/ijim.v12i2.8081

[5] Teo, T., Fan, X., and Du, J. (2015). Technology acceptance among pre-service teachers: Does gender matter? Australasian Jornal of Educational Technology. 31: 235-251. https:// doi.org/10.14742/ajet.1672

[6] Bernik, A., Vusić, D., and Milković, M. (2019). Evaluation of gender differences based on knowledge adaptation in the field of gamification and computer science. International Journal of Emerging Technology in Learning, 14: 220-228. https://oi.org/10.3991/ijet. v14i08.9847

[7] Okagbue, H. I., Bishop, Sh. A., Boluwajoko, A. E., Ezenkwe, A. M., Anene, G. N., Akinsola, B. E., and Offiah, I. B. (2020). Gender and Age Differences in the Study Plan of University Students. International Journal of Interactive Mobile Technologies, 14: 62-81. https://doi. org/10.3991/ijim.v14i01.11232

[8] Zittleman, K., and Sadker, D. (2003). Teacher education and gender equity: The unfinished revolution. Educational Leadership, 60: 59-62.

[9] Schweder, S., and Raufelder, D. (2019). Positive emotions, learning behavior and teacher support in self-directed learning during adolescence: Do age and gender matter? Adolescence. 73: 73-84. https://doi.org/10.1016/j.adolescence.2019.04.004

[10] Pierce, J. R., and Thompson, L. (2018). Explaining differences in men and women's use of unethical tactics in negotiations. Negotiation and Conflict Management Research, 11: 278-297. https://doi.org/10.1111/ncmr.12135

[11] Prakash, J., Kotwal, A. S. M., Ryali, V. S., Srivastava, K., Bhat, P. S., and Shashikumar, R. (2010). Does androgyny have psychoprotective attributes? A cross-sectional community-based study. Industrial psychiatry journal. 19:119-124. https://doi.org/10.4103/0972-6748.90343 
[12] Kravtsov, Y. S., Chetnverikova, N. A., Saifnazarov, I. S., Dombrovska, O. V., \& Khovpun, O. S. (2019). Philosophical purpose of social communication in the aspects of sustainable development of modern social reality. Asia Life Sciences, 21: 329-337.

[13] Kimmel, M. S. (2000). The Gendered Society. Gender and Society, 14: 827-829. https://doi. org/10.1177/089124300014004002

[14] Erikson, E. H. (1959). Identity and the life cycle. New York: International Universities Press, 192.

[15] Liu, Z. J., Tretyakova, N., Fedorov, V., \& Kharakhordina, M. (2020). Digital literacy and digital didactics as the basis for new learning models development. International Journal of Emerging Technologies in Learning (iJET), 15(14), 4-18. https://doi.org/10.3991/ijet. v15i14.14669

[16] Naveed, Q. N., Qureshi, M. R. N., Tairan, N., Mohammad, A., Shaikh, A., Alsayed, A. O., ... \& Alotaibi, F. M. (2020). Evaluating critical success factors in implementing E-learning system using multi-criteria decision-making. Plos one, 15(5), e0231465. https://doi. org/10.1371/journal.pone.0231465

[17] Smolyaninova, O., \& Bezyzvestnykh, E. (2019). Implementing Teachers' Training Technologies at a Federal University: E-portfolio, Digital Laboratory, PROLog Module System. International Journal of Online \& Biomedical Engineering, 15(4). https://doi.org/10.3991/ ijoe.v15i04.9288

[18] Muhammad, A., Shaikh, A., Naveed, Q. N., \& Qureshi, M. R. N. (2020). Factors affecting academic integrity in E-learning of Saudi Arabian Universities. An investigation using Delphi and AHP. IEEE Access, 8, 16259-16268. https://doi.org/10.1109/ACCESS.2020. $\underline{2967499}$

[19] Bilyalova, A., Bazarova, L., Salimova, D., \& Patenko, G. (2021). The Digital Educational Environment: The Problem of Its Accessibility for Visually Impaired Students. International Journal of Emerging Technologies in Learning, 16(16). https://doi.org/10.3991/ijet. $\underline{\mathrm{v} 16 \mathrm{i} 16.23453}$

[20] Naveed, Q. N., Qureshi, M. R. N. M., Shaikh, A., Alsayed, A. O., Sanober, S., \& Mohiuddin, K. (2019). Evaluating and ranking cloud-based e-learning critical success factors (CSFs) using combinatorial approach. IEEE Access, 7, 157145-157157. https://doi.org/10.1109/ ACCESS.2019.2949044

\section{Authors}

Jel̦ena Badjanova, Departments of Pedagogy and Educational Psychology, Faculty of Education and Management, Daugavpils University, Latvia.

Dzintra Iliško, Institute of Humanities and Social Sciences, Centre of Sustainable Education, Daugavpils University, Latvia. E-mail: dzintra.ilisko@du.lv

Svetlana Ignatjeva, Head of the Departments of Information Science, Faculty of Natural Sciences and Mathematics, Daugavpils University, Latvia. E-mail: svetlana. ignatjeva@du.lv

Margarita Nesterova, Departments of Pedagogy and Educational Psychology, Faculty of Education and Management, Daugavpils University, Latvia. E-mail: margarita.nesterova@du.lv

Article submitted 2021-09-26. Resubmitted 2021-10-26. Final acceptance 2021-10-27. Final version published as submitted by the authors. 